\title{
Effects of enzyme replacement therapy in Fabry disease-A comprehensive review of the medical literature
}

\author{
Olivier Lidove, $M D^{1}$, Michael L. West, $M D^{2}$, Guillem Pintos-Morell, MD ${ }^{3}$, Ricardo Reisin, MD ${ }^{4}$, \\ Kathy Nicholls, $M D^{5}$, Luis E. Figuera, $M D^{6}$, Rossella Parini, $M D^{7}$, Luiz R. Carvalho, $M D^{8}$, \\ Christoph Kampmann, $M D^{9}$, Gregory M. Pastores, $M D^{10}$, and Atul Mehta, MD ${ }^{11}$
}

\begin{abstract}
Enzyme replacement therapy with $\alpha$-galactosidase A has been used to treat Fabry disease since 2001. This article reviews the published evidence for clinical efficacy of the two available enzyme preparations. We focused on heart, kidney, and nervous system manifestations, which impact both quality of life and overall prognosis. A literature search was undertaken to identify prospective open or randomized controlled trials of enzyme replacement therapy in patients with Fabry disease published since 2001. To date, no definitive conclusion can be drawn from studies that have directly compared therapeutic responses between the two commercially available enzyme preparations. Significant clinical benefits of enzyme replacement therapy have been demonstrated, mainly in patients at an early phase of the disease, with beneficial effects on heart, kidneys, pain, and quality of life in treated patients. Incidence of antibodies against agalsidase alfa and agalsidase beta observed during major clinical studies suggests a greater antigenic response to agalsidase beta. Further studies are required to confirm the long-term clinical benefits of enzyme replacement therapy. More studies with female patients are needed as are investigations of
\end{abstract}

From the ${ }^{1}$ Hôpital Bichat, Paris, France; ${ }^{2}$ Dalhousie University, Halifax, Nova Scotia, Canada; ${ }^{3}$ Germans Trias i Pujol University Hospital, Badalona, Spain; ${ }^{4}$ Hospital Britanico, Buenos Aires, Argentina; ${ }^{5}$ Royal Melbourne Hospital, Parkville, Australia; ${ }^{6}$ Division de Genetica, Centro de Investigación Biomédica de Occidente-Instituto Mexicano del Seguro Social (CIBO-IMSS), Guadalajara, Mexico; ${ }^{7}$ Ospedale San Gerardo, Clinica Pediatrica, Monza, Italy; ${ }^{8}$ Servico de Terapia Renal de Ourinhos (STRO), Ourinhos, Sao Paulo, Brazil; ${ }^{9}$ Klilnikun der J.G. Universität, Kinderklinik and Poliklinik, Mainz, Germany; ${ }^{10}$ New York University School of Medicine, New York City, New York; and ${ }^{11}$ The Royal Free Hospital, London, United Kingdom.

Olivier Lidove, MD, Department of Internal Medicine, Hôpital Bichat, 46 rue Henri Huchard, 75877 Paris Cedex 18, France. E-mail: olivier. lidove@bch.aphp.fr.

Disclosure: Dr. Lidove has received support and/or travel fees from Shire HGT, Actelion, and Genzyme. Dr. West has received honoraria, research funding, speaker's fees, and/or travel expenses from Shire HGT, Genzyme, and Amicus. Dr. Pintos-Morell has received honoraria, research funding, and/or travel expenses from Shire HGT. Dr. Reisin has received honoraria, research funding, and/or travel expenses from Shire HGT, Genzyme, Pfizer, and Novartis. Dr. Nicholls is a member of the Global Fabry Advisory Board and the Fabry Outcome Survey International Advisory Board. She has received travel and research support from Shire HGT and Genzyme. She is a member of the Australian Fabry Disease Advisory Committee of the Australian Lifesaving Drug Program. Drs. Carvalho and Figuera have received honoraria, research funding, and/or travel expenses from Shire HGT and Genzyme. Drs. Kampmann and Parini have received honoraria, research funding, and/or travel expenses from Shire HGT, Genzyme, and Biomarin. Dr. Pastores has received honoraria, research funding, and/or travel expenses from Shire HGT, Genzyme, Amicus, Biomarin, and Protalix. Dr. Mehta has received honoraria, research funding, consultancy fees, and travel expenses from Shire HGT, Genzyme, Actelion, Protalix, and Amicus.

Submitted for publication March 17, 2010.

Accepted for publication July 9, 2010.

Published online ahead of print October 18, 2010

DOI: $10.1097 /$ GIM.0b013e3181f13b75 early initiation of enzyme replacement therapy to determine the optimal time to start treatment to prevent irreversible organ damage. The value of adjunctive and supportive therapies should also be rigorously analyzed. Genet Med 2010:12(11):668-679.

Key Words: antibodies, clinical efficacy, enzyme therapy, Fabry disease, symptomatic therapy, tolerance

Eabry disease is an X-linked metabolic disorder caused by a - deficiency in the lysosomal enzyme, $\alpha$-galactosidase A ( $\alpha$-gal A) (OMIM \#301500). ${ }^{1}$ As a consequence, the enzyme's primary incompletely catabolized substrate, globotriaosylceramide (Gb3), accumulates in cells and organs throughout life. This accumulation leads to multiorgan pathology that most seriously affects the kidneys, heart, and cerebrovascular system..$^{2-4}$ The initial signs and symptoms of Fabry disease emerge during childhood and adolescence and typically include neuropathic pain crises, angiokeratomas, hypohidrosis, and gastrointestinal problems, including diarrhea, constipation, abdominal pain, and nausea and vomiting. ${ }^{5-7}$ However, because these signs and symptoms are not specific to Fabry disease, these patients are frequently misdiagnosed, and the correct diagnosis may be delayed.

Major organ involvement typically has its clinical presentation between the age of 20 and 30 years. Kidney dysfunction occurs in nearly all men with Fabry disease and usually presents with mild proteinuria followed by progressive loss of glomerular filtration rate (GFR). ${ }^{8}$ By the age of 40 years, end-stage renal disease is usually reached. ${ }^{9-12}$ Cardiac disease, including progressive development of left ventricular hypertrophy (LVH), valve thickening, and conduction abnormalities leading to dysfunction, is common. ${ }^{13}$ Stroke is common, with a prevalence of up to $7.0 \%$ in Fabry patient registries. ${ }^{14,15}$ Despite their usual indolent behavior, these major organ pathologies are the principal cause of morbidity and premature mortality in patients with Fabry disease. ${ }^{8,15,16}$ Major organ involvement has also been reported in children and adolescents, including substantial reduction in GFR and proteinuria, 6,17 LVH, 7,18 and stroke. ${ }^{19,20}$ The major organ involvement combined with the other pathologies of Fabry disease also result in a significantly decreased quality of life for both affected adults ${ }^{21-23}$ and children. ${ }^{5}$

\section{ENZYME REPLACEMENT THERAPY FOR FABRY DISEASE}

Enzyme replacement therapy (ERT) with $\alpha$-gal A has been commercially available since 2001. Two different forms are available. Agalsidase alfa (Replagal ${ }^{\circledR}$, Shire Human Genetic Therapies, Inc., Cambridge, MA) is produced in a human cell line by gene activation. ${ }^{24,25}$ It is administered by intravenous infusion at $0.2 \mathrm{mg} / \mathrm{kg}$ every other week (EOW) over approximately 40 minutes, usually without routine premedication. Agalsidase beta (Fabrazyme ${ }^{\circledR}$, Genzyme Corporation, Cam- 
bridge, MA) is produced in Chinese hamster ovary cells by recombinant techniques ${ }^{25}$ and is administered by intravenous infusions EOW at a dose of $1.0 \mathrm{mg} / \mathrm{kg}$. Premedication (antipyretic and/or antihistamine) is routinely used. Both enzymes are available in Europe and many other countries. ${ }^{26,27}$ Agalsidase alfa failed to gain US Food and Drug Administration approval for marketing, and therefore, only agalsidase beta is available in United States. In February 2008, European Union approval of agalsidase beta under exceptional circumstances was lifted to normal approval. ${ }^{28}$

The regulatory approval of both drugs was based on the results of randomized, placebo-controlled clinical trials of each preparation. In a group of 26 adult male patients, agalsidase alfa reduced the severity of neuropathic pain compared with placebo after 6 months and seemed to stabilize renal function during up to 4.5 years of treatment. ${ }^{29,30}$ A significant reduction in QRS-complex duration was also observed. In a second study, 6 months of agalsidase alfa reduced left ventricular mass (LVM) in adult men compared with placebo. ${ }^{31}$ The results of a third randomized clinical trial of agalsidase alfa in adult men have been combined with the results of the two studies cited above in a summary analysis of the effects of agalsidase alfa on kidney function as assessed by measured GFR. ${ }^{32}$ This analysis demonstrated that GFR was stabilized in patients with mild-to-moderate kidney dysfunction at baseline and that this benefit was primarily seen in patients with baseline proteinuria $<1 \mathrm{~g} /$ day.

Agalsidase beta has been the subject of two randomized clinical trials. In a group of 56 men and two women with Fabry disease, agalsidase beta cleared Gb3 deposits from skin and heart after 6 months $^{33}$ and seemed to stabilize kidney function during the 4-year, open-labeled extension study. ${ }^{34}$ The second study was conducted with a patient population with evidence of kidney dysfunction, and the group treated with agalsidase beta demonstrated an increase in the time to first major renal, cardiac, or cerebrovascular event compared with placebo $(P=$ 0.06). ${ }^{35}$ This benefit was most prominent in patients with baseline proteinuria $<1 \mathrm{~g}$ /day.

The availability of ERT has led to an increased interest in Fabry disease and its treatment as evidenced by the nearly 5 -fold increase in the number of articles published per year from 2001, when the results of the initial clinical trials of ERT for Fabry disease were published, to the first 6 months of 2009 (Fig. 1). In addition to case reports and review articles, these articles include descriptions of investigator-initiated studies in adult men and in children ${ }^{19,36,37}$ and women ${ }^{38}$ with Fabry disease. The purpose of the present report is to provide a comprehensive review of the literature on the clinical efficacy of ERT in the treatment of Fabry disease.

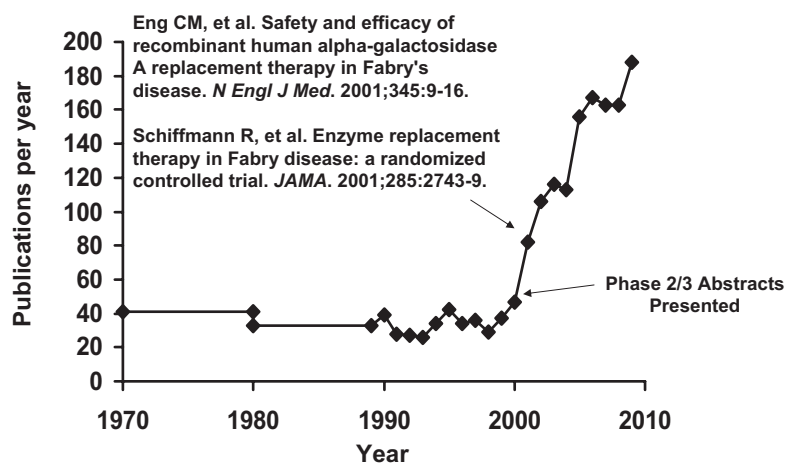

Fig. 1. The number of Fabry disease-related articles published in the medical literature from 1970 to 2009.

\section{MATERIALS AND METHODS}

In April 2009, Shire Human Genetic Therapies, Inc. (Shire HGT, Cambridge, MA) invited an international group of physicians from Europe, North America, Australia, and South America who have extensive clinical experience in the management and treatment of Fabry disease to a meeting in Frankfurt, Germany, to discuss evidence relating to the use of ERT in treatment of Fabry disease and to propose treatment goals. The idea for and the decision to write this review and the companion article discussing therapeutic goals of ERT in the treatment of Fabry disease ${ }^{39}$ was made by the physician members of this advisory board.

A systematic search of the PubMed database was conducted using the following search strategy: ("Fabry* disease") AND ("agalsidase" OR "enzyme replacement" OR "Replagal" OR "Fabrazyme"). The search was restricted to the period starting January 1, 2001, and ending December 31, 2009. Case reports and review articles were excluded from this summary, as were retrospective studies (with the exception of studies that retrospectively analyzed data collected during the conduct of randomized clinical trials) (e.g., Refs. 32 and 40). In addition, studies that reported only biochemical changes during ERT were excluded from the summary. Finally, the regulatory documents that have been filed with the European Medicines Agency were also reviewed for any additional information that may have not yet been published.

\section{RESULTS}

A total of 499 articles meeting the search criteria were identified. Forty-eight of these reports described prospective clinical studies of ERT for Fabry disease: 22 described the use of agalsidase alfa, 22 described the use of agalsidase beta, and four described pooled results of patients treated with either preparation. ${ }^{41-44}$

Table 1 presents a summary of the results of these studies, focusing on major organ involvement, including kidney dysfunction, cardiac structure and function, and cerebrovascular changes and other symptoms that adversely affect quality of life, including neuropathic pain and gastrointestinal problems. In the remainder of this report, we will present a summary of these studies and their results. We present them in an order that has relevance in terms of the goals of ERT in Fabry disease. These primary treatment goals include (1) preservation of kidney function; (2) improvement of cardiac structure and function; (3) improvement of neurologic symptoms, mainly prevention of stroke; and (4) improvement of quality of life by reducing the prevalence and severity of pain.

\section{Kidney function}

Kidney dysfunction is nearly universal in men with Fabry disease. Initial presentation is typically with microalbuminuria or proteinuria with an age of onset as early as 7 years ${ }^{77}$ and a prevalence exceeding $50 \%$ by the age of 35 years. ${ }^{78}$ A progressive loss of filtering capacity begins at about the same age and will usually advance to end-stage renal disease by an average age of between 37 and 42 years. ${ }^{9}$ The loss of filtering capacity may be preceded by a period of abnormally high GFR, or hyperfiltration, in some patients. ${ }^{32}$ Female heterozygotes may also experience kidney disease, but it is usually less severe and progresses more slowly than in men. ${ }^{8}$ Of note, about $12 \%$ of patients with Fabry disease on hemodialysis are women in both American and European cohorts. ${ }^{9,80}$ 
Table 1 Overview of clinical efficacy of enzyme replacement therapy for Fabry disease

\begin{tabular}{|c|c|c|}
\hline & Agalsidase alfa & Agalsidase beta \\
\hline \multirow[t]{2}{*}{ Neuropathic pain } & $\begin{array}{l}\text { - Significant reduction in pain scores } \\
\text { compared with placebo }{ }^{29}\end{array}$ & - Small, insignificant decrease ${ }^{45}$ \\
\hline & & - Reduction in pain in both active and placebo groups ${ }^{33}$ \\
\hline Acroparesthesia & $\begin{array}{l}\text { - Significant reduction in prevalence from } \\
\text { baseline }{ }^{41^{a}}\end{array}$ & \\
\hline Nerve function & $\begin{array}{l}\text { - Significant improvement in cold and heat } \\
\text { sensation threshold in the foot }{ }^{46}\end{array}$ & - Significant improvement in nerve function ${ }^{47}$ \\
\hline & - No change in thermal threshold in the thigh ${ }^{48}$ & \\
\hline Vestibular/auditory & $\begin{array}{l}\text { Improved vestibular function with no } \\
\text { change in auditory function }{ }^{48}\end{array}$ & \\
\hline
\end{tabular}

- Improved hearing 50

Kidney

Heart

QoL fractional shortening 41 in boys ${ }^{19}$

- Stability of measured GFR more than 2 yr of treatment, no effect on proteinuria, proteinuria $>1 \mathrm{~g} /$ day predicts continued decline in $\mathrm{GFR}^{32}$

- Stability of eGFR in men with Stage 1 or 2 $\mathrm{CKD}^{30}$ during a 4.5 -yr period

- Improved creatinine clearance compared with placebo. ${ }^{29}$ Stability of measured GFR

- Stable or improved eGFR in women, improved proteinuria in women with baseline exceeding $300 \mathrm{mg} /$ day $^{38}$

- Slight increase in eGFR in transplant patients ${ }^{56}$

- No change in LVM, small increase in

- Significant reduction in MRI-measured LVM compared with placebo ${ }^{31}$

- Improved cardiac conduction ${ }^{29}$ in one case

- Significantly reduced LVM in women with LVH, improved NYHA scores ${ }^{38}$

- Significantly improved heart rate variability

(2)


Table 1 Continued

\begin{tabular}{|c|c|c|}
\hline & Agalsidase alfa & Agalsidase beta \\
\hline CNS & $\begin{array}{l}\text { - Strokes occur during treatment }{ }^{30} \\
\text { - Increase in number of white matter lesions }{ }^{67} \\
\text { - Appearance and disappearance of white matter } \\
\text { lesions }{ }^{68} \\
\text { - Correction of abnormally elevated cerebral } \\
\text { blood flow and cerebrovascular responses }{ }^{69,70}\end{array}$ & $\begin{array}{l}\text { - Strokes occur during treatment }{ }^{53} \\
\text { - Increase in number of white matter lesions }{ }^{43}\end{array}$ \\
\hline Sweat function & $\begin{array}{l}\text { - No change } 2 \text { days or } 2 \text { weeks after treatment } \\
\text { - Improved sweat function } \\
\text { - Apparent improvement in sympathetic skin } \\
\text { response }^{72}\end{array}$ & \\
\hline GI & - Reduced severity and frequency of GI pain ${ }^{73}$ & \\
\hline MSSI & $\begin{array}{l}\text { - Significant reduction in total, general, } \\
\text { neurologic, and cardiovascular scores } \\
\text { - Improvement in total, neurologic, and } \\
\text { cardiovascular scores in women } \\
\text { - Significant reduction in MSSI in men and } \\
\text { women }^{75}\end{array}$ & \\
\hline Cardiopulmonary function & $\begin{array}{l}\text { - Improvement in NYHA classification in } \\
\text { women }^{38}\end{array}$ & - No significant changes ${ }^{76}$ \\
\hline Children & $\begin{array}{l}\text { - Well tolerated, appears to decrease pain }{ }^{36} \\
\text { - Significantly improved heart rate variability in } \\
\text { boys, decrease in pain medication }{ }^{19}\end{array}$ & - Well tolerated, GI involvement improved ${ }^{37}$ \\
\hline Women & $\begin{array}{l}\text { - Improved LVM and } \mathrm{QoL}^{66} \\
\text { - Improvements in heart, kidney, pain, and } \\
\text { MSSI }^{38}\end{array}$ & \\
\hline
\end{tabular}

${ }^{a}$ Twenty-two of 27 treated with agalsidase alfa.

${ }^{b}$ Dose decreased from 1.0 to $0.3 \mathrm{mg} / \mathrm{kg}$ EOW after Week 24

${ }^{c}$ Thirty of 33 patients were treated with agalsidase beta.

GFR, glomerular filtration rate; eGFR, estimated GFR; CKD, chronic kidney disease; ERT, enzyme replacement therapy; ACE, angiotensin converting enzyme; ARBs, angiotensin receptor blockers; GI, gastrointestinal; LVM, left ventricular mass; MRI, magnetic resonance imaging; LVEDV, left ventricular end diastolic volume; NYHA, New York Heart Association; LV, left ventricular; QoL, quality of life; SF-36, Short Form-36; GI, gastrointestinal; MSSI, Mainz Severity Score Index.

Some children and adolescents also have kidney dysfunction. For example, in the Fabry Registry study of children with Fabry disease, 2 of 71 boys and 1 of 73 girls had estimated GFR (eGFR) $<90 \mathrm{~mL} /$ minute/1.73 $\mathrm{m}^{2} .{ }^{17}$ Proteinuria was found in 4 of 42 boys and 5 of 44 girls for whom 24-hour urinary protein measurements were available. Of interest is a report that glomerular and renal vascular morphological changes were clearly present in renal biopsy samples from nine children with Fabry disease aged 7-18 years who demonstrated microalbuminuria or proteinuria. ${ }^{76}$

\section{Effect of agalsidase alfa}

In an open-labeled extension study, mean eGFR did not change significantly in 20 adult male patients with baseline eGFR $\geq 60 \mathrm{~mL} /$ minute $/ 1.73 \mathrm{~m}^{2}$ during $4-4.5$ years of agalsidase alfa, although two of eight patients with baseline eGFR between 60 and $90 \mathrm{~mL} /$ minute $/ 1.73 \mathrm{~m}^{2}$ demonstrated loss of eGFR to below $60 \mathrm{~mL} /$ minute $/ 1.73 \mathrm{~m}^{2}$ during the study. ${ }^{30}$

West et al. ${ }^{32}$ have recently combined the renal results of the above study with the results of two other randomized clinical trials of agalsidase alfa in adult male patients. During a 6-month placebo treatment period, GFR measured by inulin or radiolabeled tracer techniques in 54 patients with baseline GFR below
$135 \mathrm{~mL} /$ minute $/ 1.73 \mathrm{~m}^{2}$ declined at an average rate of $7.0 \pm$ $32.9 \mathrm{~mL} /$ minute $/ 1.73 \mathrm{~m}^{2} /$ year (mean $\pm \mathrm{SD}$ ). During $1-4.5$ years of agalsidase alfa (mean $2.1 \pm 1.1$ year), the mean rate of decline in GFR was $2.9 \pm 8.7 \mathrm{~mL} /$ minute $/ 1.73 \mathrm{~m}^{2} /$ year $(n=$ $85)$. No statistical analysis of these rates was reported. Thirtysix patients who had GFR $<135 \mathrm{~mL} /$ minute $/ 1.73 \mathrm{~m}^{2}$ before or during the placebo period were also treated with agalsidase alfa for at least 12 months. In this subgroup of patients, GFR declined at a rate of $10.5 \mathrm{~mL} /$ minute $/ 1.73 \mathrm{~m}^{2} /$ year during the placebo period, but after switching to agalsidase alfa, GFR remained stable, declining by only $0.1 \mathrm{~mL} /$ minute $/ 1.73 \mathrm{~m}^{2} /$ year $(P=0.097$ compared with placebo). Agalsidase alfa had no effect on proteinuria during this study. An important finding in this study was that baseline proteinuria $>1$ g/day was significantly associated with continued and rapid loss of GFR during treatment with agalsidase alfa (Fig. 2). This summary analysis is the only study to report on the renal effects of ERT in Fabry disease using measured GFR rather than eGFR. This fact is important because the use of eGFR has never been validated in Fabry disease, and the West study showed that eGFR overestimated measured GFR by about $25 \%$ in adult men. 


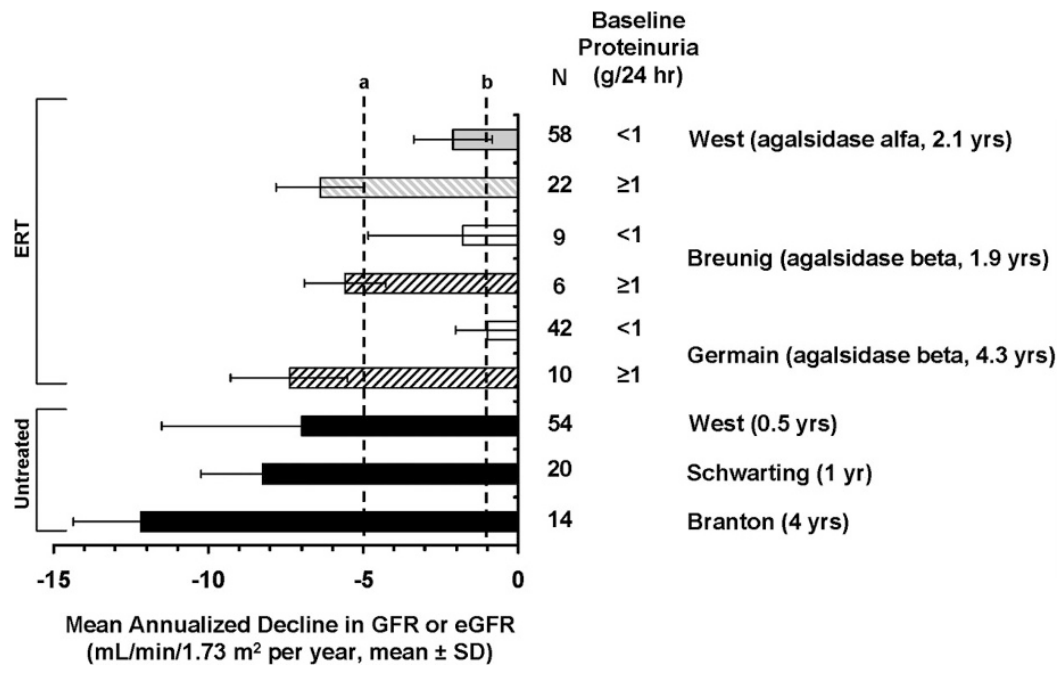

Fig. 2. A summary of rates of change of glomerular filtration rate (GFR) in Fabry disease with or without enzyme replacement therapy (ERT). Referenced in this figure: West (agalsidase alfa, 2.1 yrs) ${ }^{32}$, Breunig (agalsida beta, 1.9 yrs) ${ }^{54}$, Germain (agalsidase beta, $4.3 \mathrm{yrs})^{34}$, West $(0.5 \mathrm{yrs})^{32}$, Schwarting $(1 \mathrm{yrs})^{79}$, Branton $(4 \mathrm{yrs})^{78}$. Adapted from $/ \mathrm{Am}$ Soc Nephrol. 2009;20:1132-1139, with permission from the American Society of Nephrology.

In a 4-year study in 36 women with Fabry disease, eGFR remained stable in patients with baseline eGFR $>90 \mathrm{~mL} /$ minute $/ 1.73 \mathrm{~m}^{2}$ or with baseline eGFR between 30 and $<60$ $\mathrm{mL} / \mathrm{minute} / 1.73 \mathrm{~m}^{2} .^{38}$ In patients with baseline eGFR between 60 and $<90 \mathrm{~mL} /$ minute $/ 1.73 \mathrm{~m}^{2}$, mean eGFR increased from $76.6 \pm 8.5$ (mean $\pm \mathrm{SEM}$ ) at baseline to $85.5 \pm 13.2$ after 1 year $(P<0.01)$ and remained significantly elevated throughout the remainder of the study. Proteinuria was significantly reduced after 3 years of agalsidase alfa in the 11 patients with baseline protein excretion in excess of $300 \mathrm{mg} /$ day.

\section{Effect of agalsidase beta}

Germain et al. ${ }^{34}$ reported that eGFR declined by about 1.1 $\mathrm{mL} /$ minute $/ 1.73 \mathrm{~m}^{2} /$ year in 58 adult patients with normal pretreatment eGFR treated with agalsidase beta for a mean of 52.2 months. Baseline proteinuria $>1 \mathrm{~g}$ /day was significantly associated with continued progressive loss of eGFR during the study (Fig. 2). Median proteinuria did not change during the study.

In a randomized, double-blinded, placebo-controlled study, agalsidase beta was associated with delayed time to first major clinical event (a composite of renal, cardiac, or cerebrovascular event or death, hazard ratio $=0.47, P=0.06$ ). When censored for failure to comply with the protocol, ERT was associated with a significant delayed time to first major clinical event, hazard ratio $=0.39, P=0.034 .{ }^{35}$ Although the majority of events in both the placebo and agalsidase beta groups were renal (i.e., a $33 \%$ increase in serum creatinine), no change in mean eGFR, serum creatinine, or proteinuria was seen in either group during the median 18.5-month study period.

The role of baseline severity of renal dysfunction in relation to ERT response was also studied by Breunig et al. ${ }^{54}$ Baseline eGFR categorized as above or below $90 \mathrm{~mL} /$ minute $/ 1.73 \mathrm{~m}^{2}$ had no apparent effect on the change in eGFR during 2 years of agalsidase beta. However, from data presented in the article, the influence of baseline proteinuria on rate of loss of eGFR could be estimated. Figure 2 shows that effect of baseline proteinuria on loss of eGFR was consistent with the other studies of ERT in Fabry disease.

The results of a recent study suggest that aggressively targeting proteinuria with angiotensin converting enzyme (ACE) inhibitors and/or angiotensin receptor blockers (ARBs) may improve the renal response to agalsidase beta in patients with mean baseline eGFR $<60 \mathrm{~mL} /$ minute $/ 1.73 \mathrm{~m}^{2} .55$ Nevertheless, severe complications were observed during this study of 11 patients (eight men and three women), including three patients with hypotension, three patients with hyperkalemia with serum $\mathrm{K}^{+}>6.0 \mathrm{mEq} / \mathrm{L}$, and three patients requiring intracardiac defibrillator devices. In addition, one patient received a kidney transplant and another progressed to end-stage renal disease during the treatment period.

\section{Cardiac involvement}

Cardiac involvement in Fabry disease is common and includes LVH, valvular dysfunction, and conduction abnormalities. ${ }^{13}$ The majority of male and female patients develop $\mathrm{LVH},{ }^{13,81}$ with an onset between the age of 20 and 30 years. ${ }^{13}$ As the disease progresses, myocardial fibrosis is common. ${ }^{82}$ Systolic function assessed by conventional methods typically remains normal, ${ }^{81}$ although subtle changes in systolic function can be detected with tissue Doppler imaging. ${ }^{83}$ Cardiac involvement is the most common cause of premature mortality in men and women with Fabry disease. ${ }^{15,16}$

\section{Effect of agalsidase alfa}

Two prospective studies of the effect of agalsidase alfa on LVM have been reported and are summarized in Table 2. Hughes et al. ${ }^{31}$ conducted a double-blinded, placebo-controlled study of agalsidase alfa in adult men $(n=15)$ with baseline LVH using magnetic resonance imaging to assess LVM. After 6 months of treatment, LVM had decreased by $11.5 \mathrm{~g}$ in the agalsidase alfa group and had increased by $21.8 \mathrm{~g}$ in the placebo group, a difference that was statistically significant $(P=0.043)$. During the 2-year, open-labeled extension of this study, LVM was not significantly changed compared with baseline, but significant decreases in LV posterior wall and septal wall thickness suggested that cardiac remodeling had occurred while on treatment with agalsidase alfa.

Whybra et al. ${ }^{38}$ treated 36 women with Fabry disease for 4 years and found sustained reductions in LVM regardless of 
Table 2 A summary of the effect of ERT on left ventricular mass

\begin{tabular}{|c|c|c|c|c|c|c|c|c|c|c|c|c|}
\hline \multirow[b]{2}{*}{ Study } & \multirow[b]{2}{*}{$\mathrm{N}$} & \multirow[b]{2}{*}{$\mathrm{M} / \mathrm{F}$} & \multirow{2}{*}{$\begin{array}{l}\text { Age } \\
\text { (yr) }\end{array}$} & \multirow{2}{*}{$\begin{array}{l}\text { Study } \\
\text { design }\end{array}$} & \multirow{2}{*}{$\begin{array}{l}\text { Control } \\
\text { group }\end{array}$} & \multirow[b]{2}{*}{ Method } & \multirow{2}{*}{$\begin{array}{l}\text { Blinded } \\
\text { evaluation }\end{array}$} & \multicolumn{5}{|c|}{ Treatment time } \\
\hline & & & & & & & & Baseline & 6 & 12 & 18 & 24 \\
\hline \multicolumn{13}{|c|}{$\begin{array}{l}\text { Agalsidase alfa, } \\
0.2 \mathrm{mg} / \mathrm{kg} \text { EOW }\end{array}$} \\
\hline \multirow[t]{2}{*}{ Hughes et al. ${ }^{31}$} & 7 & $7 / 0$ & 37 & DB & Placebo & MRI & NR & $276 \mathrm{~g}$ & $265 \mathrm{~g}^{a}$ & $b$ & $b$ & $b$ \\
\hline & 7 & $7 / 0$ & 37 & & & & & $248 \mathrm{~g}$ & $270 \mathrm{~g}$ & & & \\
\hline \multirow[t]{5}{*}{ Whybra et al. ${ }^{38}$} & 36 & $0 / 36$ & 47 & OL, $\mathrm{P}$ & None & Echocardiogram & NR & 131.9 & & $98.1^{c}$ & & $98.1^{c}$ \\
\hline & (9) & & & & & & & 76.3 & & $57.4^{c}$ & & $56.5^{c}$ \\
\hline & (9) & & & & & & & 56.0 & & $44.0^{c}$ & & $44.0^{c}$ \\
\hline & (8) & & & & & & & 40.7 & & $35.3^{d}$ & & $35.3^{d}$ \\
\hline & (11) & & & & & & & $\mathrm{g} / \mathrm{m}^{2.7}$ & & $\mathrm{~g} / \mathrm{m}^{2.7}$ & & $\mathrm{~g} / \mathrm{m}^{2.7}$ \\
\hline \multicolumn{13}{|c|}{$\begin{array}{l}\text { Agalsidase beta } \\
\qquad 1.0 \mathrm{mg} / \mathrm{kg} \text { EOW }\end{array}$} \\
\hline Pisani et al. ${ }^{57}$ & 6 & ND & ND & $\mathrm{OL}, \mathrm{P}$ & None & Echocardiogram & Yes & $73 \mathrm{~g} / \mathrm{m}^{2.7}$ & & $74 \mathrm{~g} / \mathrm{m}^{2.7}$ & & $75 \mathrm{~g} / \mathrm{m}^{2.7}$ \\
\hline Elliott et al. ${ }^{59}$ & 5 & $5 / 0$ & 53.8 & $\mathrm{OL}, \mathrm{P}$ & None & PET & NR & $226.3 \mathrm{~g} / \mathrm{m}^{2}$ & & $226.7 \mathrm{~g} / \mathrm{m}^{2}$ & & \\
\hline $\begin{array}{l}\text { Kalliokoski } \\
\text { et al. }{ }^{65}\end{array}$ & 7 & $4 / 3$ & 38.5 & $\mathrm{OL}, \mathrm{P}$ & None & Echocardiogram & NR & $151 \mathrm{~g} / \mathrm{m}^{2}$ & & $156 \mathrm{~g} / \mathrm{m}^{2}$ & & \\
\hline $\begin{array}{l}\text { Weidemann } \\
\text { et al. }{ }^{63}\end{array}$ & 10 & ND & ND & OL, $\mathrm{P}$ & None & MRI & NR & $208 \mathrm{~g}$ & & $180 \mathrm{~g}^{e}$ & & \\
\hline Spinelli et al. ${ }^{62}$ & 9 & $7 / 2$ & 40.8 & $\mathrm{OL}, \mathrm{P}$ & None & Echocardiogram & Yes & $183 \mathrm{~g} / \mathrm{m}^{2}$ & & $170 \mathrm{~g} / \mathrm{m}^{2 d}$ & & \\
\hline \multirow[t]{2}{*}{ Vedder et al. ${ }^{42}$} & $8^{f}$ & NR & NR & $\mathrm{OL}, \mathrm{P}$ & None & Echocardiogram & NR & $\mathrm{NR}^{g}$ & & $-65 \mathrm{~g}^{e}$ & & \\
\hline & $6^{h}$ & NR & NR & & & & & & & $-77 \mathrm{~g}^{e}$ & & \\
\hline \multirow[t]{2}{*}{ Breunig et al. ${ }^{54}$} & $9^{i}$ & $5 / 4$ & 38.2 & $\mathrm{OL}, \mathrm{P}$ & None & Echocardiogram & Yes & $11.7 \mathrm{~mm}^{j}$ & & & $10.7 \mathrm{~mm}^{e}$ & \\
\hline & $16^{k}$ & $14 / 2$ & 43 & & & & & $14.0 \mathrm{~mm}$ & & & & $13.4 \mathrm{~mm}$ \\
\hline \multirow[t]{2}{*}{ Beer et al. ${ }^{64}$} & $8^{l}$ & ND & ND & $\mathrm{OL}, \mathrm{P}$ & None & MRI & NR & $211 \mathrm{~g}$ & & $195 \mathrm{~g}$ & & \\
\hline & $9^{m}$ & ND & ND & & & & & $160 \mathrm{~g}$ & & $145 \mathrm{~g}^{d}$ & & \\
\hline \multirow{3}{*}{$\begin{array}{l}\text { Weidemann } \\
\text { et al. }{ }^{61}\end{array}$} & $12^{m}$ & NR & 36 & OL, $\mathrm{P}$ & None & Echocardiogram & Yes & $238 \mathrm{~g}$ & & $213 \mathrm{~g}$ & & $202 \mathrm{~g}^{n}$ \\
\hline & 11 & NR & 42 & $\mathrm{OL}, \mathrm{P}$ & & & & $275 \mathrm{~g}$ & & $244 \mathrm{~g}$ & & $244 \mathrm{~g}^{n}$ \\
\hline & $9^{l}$ & NR & 50 & OL, P & & & & $303 \mathrm{~g}$ & & $255 \mathrm{~g}$ & & $247 \mathrm{~g}^{n}$ \\
\hline Imbriaco et al. ${ }^{60}$ & 11 & $8 / 3$ & 35 & OL, P & None & MRI & NR & $188 \mathrm{~g}$ & & & & $153^{c, o}$ \\
\hline
\end{tabular}

Reprinted from Clinical Therapeutics. 2009;31:1966-1976 (Kampmann et al.), with permission from Excerpta Medica, Inc.

${ }^{a} P<0.05$ for the comparison of changes observed in the agalsidase alfa group and the placebo group.

${ }^{b}$ No change from baseline for the 10 patients who participated in open-label treatment.

${ }^{c} P<0.001$ compared with baseline.

${ }^{d} P<0.01$.

${ }^{e} P<0.05$.

${ }_{\mathrm{IgG}}$ antibody negative at the end of the study.

${ }^{g}$ Average LVM for 18 patients treated with agalsidase beta.

${ }^{h} \mathrm{IgG}$ antibody positive at end of study.

${ }^{i}$ Glomerular filtration rate $($ GFR $)>90 \mathrm{~mL} / \mathrm{min} / 1.73 \mathrm{~m}^{2}$.

${ }^{j}$ Posterior wall thickness.

${ }^{k} \mathrm{GFR}<90 \mathrm{~mL} / \mathrm{min} / 1.73 \mathrm{~m}^{2}$.

${ }^{l}$ Myocardial fibrosis at baseline.

${ }^{m}$ No myocardial fibrosis at baseline.

${ }^{n}$ Thirty-six months time point. $P=0.01$ for the overall effect of ERT over time.

${ }^{\circ} 45$ months.

M/F, male/female; ERT, enzyme replacement therapy; EOW, every other week; DB, double blind; MRI, magnetic resonance imaging; NR, not reported; OL, open label;

$\mathrm{P}$, prospective; ND, cannot be determined from data presented in the article; PET, positron emission tomography.

baseline LVM. For example, nine patients with baseline LVM indexed to height between 60 and $85 \mathrm{~g} / \mathrm{m}^{2.7}$ demonstrated a reduction from $76.3 \pm 9.9 \mathrm{~g} / \mathrm{m}^{2.7}$ at baseline to $57.4 \pm 13.3$ $\mathrm{g} / \mathrm{m}^{2.7}$ after 1 year $(P<0.001)$. This significant reduction was sustained throughout the 4 years of treatment. Similar reductions were observed in subgroups with baseline LVM between 48 and $60 \mathrm{~g} / \mathrm{m}^{2.7}$ and $>85 \mathrm{~g} / \mathrm{m}^{2.7}$. In addition to the morphological improvement, the average New York Heart Association 
heart failure classification was improved significantly during treatment with agalsidase alfa.

\section{Effect of agalsidase beta}

The effect of agalsidase beta on LVM has been investigated in 10 open-labeled clinical studies (Table 2). Three of the studies reported no change in LVM after 1 or 2 years of agalsidase beta treatment. ${ }^{57,59,65}$ Of note, the primary endpoint of two of these studies was to assess myocardial blood flow and coronary flow reserve ${ }^{59}$ and myocardial perfusion reserve. ${ }^{65}$ The remaining studies found a significant decrease in LVM in either the entire study population or in one or more subgroups. ${ }^{42,54,60-64}$ Of interest are the two studies in which patients were grouped according to the presence or absence of myocardial fibrosis. Myocardial fibrosis is seen in the late stages of Fabry cardiomyopathy and is associated with increased LVM and a reduction in function. ${ }^{84}$ Beer et al. ${ }^{64}$ used gadoliniumenhanced magnetic resonance imaging to detect the presence of increased myocardial collagen content. LVM in the eight patients with evidence of fibrosis at baseline did not change significantly after 1 year of treatment. In contrast, LVM of the nine patients without fibrosis declined from $160 \pm 23 \mathrm{~g}$ at baseline to $145 \pm 27 \mathrm{~g}$ at 1 year $(P=0.008)$. Weidemann et al. ${ }^{61}$ conducted a similar study in which they compared the response to 3 years of agalsidase beta in patients with no fibrosis, mild fibrosis, and severe fibrosis at baseline. Posterior wall thickness and LVM decreased significantly in all three groups. Radial and longitudinal function measured by color Doppler imaging was reduced at baseline in each of the three groups. During the 3 years of agalsidase beta, a significant increase in peak systolic strain rate of the posterior wall was seen only in patients with no fibrosis. This group also demonstrated a small but significant improvement in exercise capacity during the study. These results were interpreted to support early initiation of ERT by the investigators.

\section{Neurologic involvement}

Patients with Fabry disease experience a variety of neurologic symptoms, including neuropathic pain, impaired sweating, and hearing deficit. ${ }^{3}$ Stroke is the most important contributor to morbidity and premature mortality with an overall prevalence of $6.9-9.0 \%$ in men and $4.3-5.2 \%$ in women in patient registries (3800 patients in all). ${ }^{14,15}$

\section{Effect of agalsidase alfa}

Schiffmann et al. ${ }^{29}$ reported that agalsidase alfa reduced the severity of neuropathic pain in a 6-month, double-blinded clinical trial. However, methodological problems with the study, including imbalance in baseline pain scores in the two groups and the requirements for intermittent withdrawal from pain medications during assessment, raise concerns about this analysis. During the open-labeled extension of this study, the patients in the original placebo group demonstrated a drop in the Brief Pain Inventory (BPI) "pain at its worst" score from 6.9 to 4.5 after 6 months of agalsidase alfa $(P=0.015) .{ }^{46}$ In women, BPI "pain at its worst" scores were significantly reduced after 1 year of treatment, and this benefit was sustained throughout the 4-year study. ${ }^{38}$ Evidence exists for a positive effect on pain in children, including the reduction in need for pain medications ${ }^{19}$ and reduction in pain scores. ${ }^{36}$

Evaluation of the effect of agalsidase alfa on peripheral nerve function has yielded inconsistent results. Schiffmann et al. ${ }^{46}$ reported an improvement in hot and cold sensation in the foot and sweating during up to 3 years of agalsidase alfa therapy but no increase in intraepidermal innervation density, suggesting that epidermal nerve fibers do not regenerate during agalsidase alfa treatment. ${ }^{48}$

Several studies have demonstrated significant functional changes in the vasculature of the brain with agalsidase alfa, ${ }^{69,70,85}$ but no effect on the incidence of stroke has been observed. Indeed stroke has been observed in some patients during treatment with agalsidase alfa in clinical trials (e.g., Refs. 29 and 38). Increases in the number of white matter lesions detected by magnetic resonance imagine during agalsidase alfa have been reported. ${ }^{43,67,68}$

A small study of adult male patients with Fabry disease reported on the effect of agalsidase alfa on hearing. ${ }^{50}$ Eleven of $15 \mathrm{men}$ had bilateral or unilateral high-frequency sensorineural hearing loss of at least $30 \mathrm{~dB}$ at baseline. During the course of 30 months of agalsidase alfa, a significant improvement was reported in the 10 patients who remained in the study. Palla et al. ${ }^{49}$ studied 37 patients treated with agalsidase alfa and reported an improvement in vestibular function within the first year of ERT, whereas auditory function did not improve during the 5-year study.

\section{Effect of agalsidase beta}

Eng et al. ${ }^{33}$ reported significant reductions in pain scores during a 6-month, double-blinded study, but baseline scores were low, and similar significant reductions were also seen in the placebo group. Hilz et al. ${ }^{47}$ found improvements in vibratory, cold, and heat-pain detection thresholds after 18 or 23 months of agalsidase beta, but some patients exhibited no change or worsening of threshold during treatment, suggesting that they had experienced irreversible changes before initiation of ERT.

No effect on the incidence of stroke has been reported for agalsidase beta, and strokes have been reported during treatment with agalsidase beta (e.g., Ref. 53). Increase in number of white matter lesions have also been reported during treatment with agalsidase beta. ${ }^{43}$

\section{Quality of life}

Men and women with Fabry disease experience decreased health-related quality of life compared with the general population, primarily as the result of pain, stroke, and cardiac and renal disease. ${ }^{21-23,66,86} \mathrm{~A}$ single study in women that used the Short Form-36 to assess quality of life showed that 6 months of agalsidase alfa significantly improved the physical summary, role-physical, and general health scores. ${ }^{66}$ No comprehensive quality of life studies in men treated with agalsidase alfa have been reported. A study of 13 men treated with agalsidase beta for 20 weeks showed statistically significant improvement in the Short Form-36 General Health and Mental Component Scale scores compared with baseline. ${ }^{45}$

\section{Gastrointestinal involvement}

Gastrointestinal disturbances, primarily abdominal pain and diarrhea, are common in men and women with Fabry disease. ${ }^{87,88}$ A single study of 11 patients treated with agalsidase alfa for 6 months observed that the frequency and severity of abdominal pain were significantly reduced and five of six patients with baseline diarrhea experienced an improvement. ${ }^{73}$ Wraith et al. ${ }^{37}$ reported that children treated with agalsidase beta for 48 weeks experienced significant reductions in the prevalence of postprandial pain and vomiting compared with baseline.

\section{General improvement}

The Mainz Severity Score Index (MSSI) is an instrument for quantifying the overall severity of the signs and symptoms of Fabry disease. ${ }^{75}$ The MSSI assigns scores based on the presence 
and severity of signs and symptoms in four areas: general, neurologic, cardiovascular, and renal. In a study including 30 patients ( 23 men and 7 women) who were treated for $1-5$ years with agalsidase alfa, total MSSI scores were significantly improved compared with baseline $(P<0.0001) .{ }^{74}$ Whybra et al. ${ }^{38}$ reported that total MSSI scores in a group of 36 women were significantly reduced after 1 year of agalsidase alfa and remained significantly reduced throughout the 4 years of treatment. Improvements in the neurologic and cardiovascular subscores were responsible for most of the improvement. No similar studies of the effect of agalsidase beta on the general response to ERT using the MSSI or other instrument (e.g., Giannini et al. ${ }^{89}$ ) have been published.

\section{Women with Fabry disease}

Fabry disease has been considered historically to affect only men, but heterozygous females may experience all the signs and symptoms of Fabry disease. The phenotypic expression of Fabry disease typically emerges about 10 years later in women than in men and has a more varied expression in terms of severity and rate of progression. ${ }^{86,87,90,91}$ In contrast to men, heterozygous women usually have $\alpha$-gal A levels that are within the normal range and do not correlate with the severity of the signs and symptoms. ${ }^{38}$

A single study, specifically designed to investigate the effect of ERT in symptomatic women with Fabry disease has been reported. Whybra et al. ${ }^{38}$ treated 36 symptomatic women with agalsidase alfa for 4 years. Significant improvements were seen in severity of pain, MSSI score, LVH, and proteinuria. These responses have been described in more detail in the appropriate sections above. Women have been included in the study populations of clinical trials of agalsidase beta (e.g., Refs. 33 and 35), but too few have been included (two in one study and 10 in the other) for robust subgroup analyses to be performed. No studies specifically designed to investigate the effects of agalsidase beta in women have been reported.

\section{Children with Fabry disease}

The signs and symptoms of Fabry disease typically emerge during childhood and adolescence. ${ }^{5-7,17,36}$ In a review of the prevalence of Fabry disease manifestations in children, PintosMorell and $\mathrm{Beck}^{92}$ reported that the most common symptoms include neuropathic pain (63\% of boys and $46 \%$ of girls), hypohidrosis (34\% of boys and 14\% of girls), and gastrointestinal problems (33\% of boys and $19 \%$ of girls). Major organ involvement, including $\mathrm{LVH}$, kidney dysfunction, and stroke may also occur in these young patients. ${ }^{92}$

Two studies of agalsidase alfa in children have been reported. Ries et al. ${ }^{19}$ treated 19 boys and 5 girls for 6 months. Agalsidase alfa was generally well tolerated, and 6 of 11 patients who were taking anticonvulsant medication for neuropathic pain at baseline were able to discontinue these medications. Sweat function was assessed by quantitative sudomotor axon reflex testing in 13 patients and showed an increase in sweat volume from $0.48 \mu \mathrm{L} / \mathrm{mm}^{2}$ at baseline to $0.73 \mu \mathrm{L} / \mathrm{mm}^{2}$ at 6 months $(P=0.06)$. Boys have decreased heart rate variability (HRV) compared with the nonFabry population, ${ }^{18}$ and in this study, all time-domain indices of HRV were improved in boys treated with agalsidase alfa. ${ }^{19}$ This study has been extended to 4 years of agalsidase alfa. ${ }^{93}$ The effect on HRV persisted throughout the extended period, and significant improvement in BPI "pain at its worst" scores were observed after 1 year of ERT. A similar open-labeled study was conducted by Ramaswami et al., ${ }^{36}$ who treated nine boys and four girls for 23 weeks. BPI pain scores tended to decrease in the study.

One study of agalsidase beta in children has been reported. Wraith et al. ${ }^{37}$ treated 14 boys and 2 girls for 48 weeks and reported a decrease in the prevalence of postprandial pain and vomiting compared with baseline.

\section{Antibodies and their influence on efficacy}

Exogenous $\alpha$-gal A would be viewed as "foreign" by most men with Fabry disease, and thus, an immune response on repeat dosing would be expected. IgG antibodies have been reported in patients treated with either agalsidase alfa or agalsidase beta (Table 3). According to data on file with the European Medicines Agency (which was supplied by Shire HGT and Genzyme Corp.), $24 \%$ of men treated with agalsidase alfa develop IgG antibodies and $89 \%$ of patients treated with agalsidase beta develop IgG antibodies. ${ }^{26,27}$ IgG antibodies have not been reported in women treated with agalsidase alfa (e.g., Ref. 38), whereas about $40 \%$ of adult women treated with agalsidase beta develop IgG antibodies (Table 3). To date, IgE antibodies have only been reported in patients treated with agalsidase beta (Table 3).

Although the information presented in Table 3 suggests that agalsidase alfa is less immunogenic than agalsidase beta, this comparison is problematic because these patients were studied in different trials under different conditions, and different methods may have been used to detect antibodies in plasma. In addition, the larger dose of agalsidase beta compared with agalsidase alfa may explain some of the difference in antigenicity. A single head-to-head trial has been conducted and found that more patients treated with the approved dose of agalsidase beta $(1.0 \mathrm{mg} / \mathrm{kg}$ EOW) developed IgG antibodies ( 8 of 10) than patients treated with the approved dose of agalsidase alfa $(0.2$ $\mathrm{mg} / \mathrm{kg}$ EOW; 4 of 10; $P=0.005)$. Nevertheless, this difference did not seem to be entirely due to the larger dose of agalsidase beta, as patients treated with a lower dose $(0.2 \mathrm{mg} / \mathrm{kg}$ EOW $)$ of agalsidase beta also developed IgG antibodies at a higher rate (six of eight patients). ${ }^{42}$

Little evidence exists to suggest that the presence of $\mathrm{IgG}$ antibodies directed against either agalsidase alfa or agalsidase beta influences the clinical response to ERT. For example, in a study of adult men treated with agalsidase alfa, the presence of IgG antibodies did not affect the rate of change of eGFR during $4-4.5$ years. $^{30}$ In a retrospective analysis of the results of the two major clinical trials of agalsidase beta, ${ }^{34,35}$ Bénichou et al. ${ }^{40}$ found no association between peak antibody titer and the rate of change of eGFR or the time to first clinical event.

Biochemical evidence has been reported that suggests that IgG antibodies may attenuate some of the response to ERT. Schiffmann et al. ${ }^{30}$ reported that patients on agalsidase alfa who were persistently IgG positive did not demonstrate a reduction in urine sediment Gb3 levels, although no effect on the reduction in plasma Gb3 levels was seen. Vedder et al. ${ }^{42}$ found no influence of antibodies on the reduction of urine Gb3 levels in patients treated with the approved dose of agalsidase beta in contrast to the attenuated response seen in the pooled cohort treated with either agalsidase alfa or agalsidase beta at 0.2 $\mathrm{mg} / \mathrm{kg}$ EOW. Again, the presence of IgG antibodies did not affect the response of plasma Gb3 during ERT. In contrast to the results of Vedder et al., other investigators have reported an 
Table 3 Incidence of antibodies observed during major clinical studies of agalsidase alfa and agalsidase beta

\begin{tabular}{|c|c|c|c|c|}
\hline Study & Study population & Duration & IgG & $\operatorname{IgE}$ or positive skin test \\
\hline \multicolumn{5}{|l|}{ Agalsidase alfa } \\
\hline Schiffmann et al. ${ }^{29,30}$ & Adult men & $4-4.5 \mathrm{yr}$ & $14 / 25(56 \%)$ & $0 / 25$ \\
\hline Hughes et al. ${ }^{31}$ & Adult men & $2-2.5 \mathrm{yr}$ & $3 / 15(20 \%)$ & $0 / 15$ \\
\hline \multirow[t]{2}{*}{ Ries et al. ${ }^{19}$} & Boys & $6 \mathrm{mo}$ & $1 / 19(5.3 \%)$ & $0 / 19$ \\
\hline & Girls & & $0 / 5$ & $0 / 5$ \\
\hline \multirow[t]{2}{*}{ Ramaswami et al. ${ }^{36}$} & Boys & $6 \mathrm{mo}$ & $1 / 9(11 \%)$ & $0 / 9$ \\
\hline & Girls & & $0 / 4$ & $0 / 4$ \\
\hline Whybra et al. ${ }^{38}$ & Adult women & $4 \mathrm{yr}$ & $0 / 36$ & $0 / 36$ \\
\hline \multicolumn{5}{|l|}{ Agalsidase beta } \\
\hline \multirow[t]{2}{*}{ Germain et al. ${ }^{34}$} & Adult men & $4-4.5 \mathrm{yr}$ & $51 / 56(91 \%)$ & $4 / 56(7.1 \%)$ \\
\hline & Adult women & & $1 / 2(50 \%)$ & \\
\hline \multirow[t]{2}{*}{ Banikazemi et al. ${ }^{35}$} & Adult men & $1 \mathrm{yr}$ & $41 / 55(75 \%)$ & $3 / 63(4.8 \%)$ \\
\hline & Adult women & & $3 / 8(38 \%)$ & \\
\hline Lubanda et al. ${ }^{52}$ & Adult men & $6 \mathrm{mo}^{a}$ & $18 / 21(86 \%)^{a}$ & NA \\
\hline \multirow[t]{2}{*}{ Wraith et al. ${ }^{37}$} & Boys & $6 \mathrm{mo}$ & $8 / 11(73 \%)$ & $b$ \\
\hline & Girls & & $0 / 2$ & $0 / 2$ \\
\hline $\begin{array}{l}\text { Patients were treated with a } \\
6 \text { mo of the study. } \\
\text { NA, not available. }\end{array}$ & $\begin{array}{l}\text { t } 1.0 \mathrm{mg} / \mathrm{kg} \text { EOW } \\
\text { tg the study to be tr }\end{array}$ & $\begin{array}{l}\text { mo of the stud } \\
\text { mmercial prod }\end{array}$ & tched to $0.3 \mathrm{mg} /$ & results reflect only the first \\
\hline
\end{tabular}

attenuation of biochemical responses in IgG-positive patients treated with agalsidase beta at $1.0 \mathrm{mg} / \mathrm{kg}$ EOW. Bénichou et al. ${ }^{39}$ investigated the effect of antibodies on the clearance of Gb3 from dermal endothelial cells in patients treated with agalsidase beta and found that the largest percentage of nonzero score was found in the group of patients with the highest antibody titers. A delayed and attenuated normalization of urine Gb3 levels was found by Ohashi et al. ${ }^{94}$ in patients treated with agalsidase beta who were IgG positive compared with the patients who remained $\operatorname{IgG}$ negative. Lubanda et al. ${ }^{52}$ found that mean urine Gb3 levels did not decline after 6 months of agalsidase beta in patients with the highest antibody titers. It must be emphasized that the measurements of Gb3 in urine, plasma, or tissue noted above do not represent biomarkers, because their magnitudes do not correlate with either the severity of the symptoms of Fabry disease or any clinical response to ERT. ${ }^{95,96}$ Thus, no conclusions about the influence of antibodies on the clinical response to ERT can be inferred from these biochemical observations.

It is important to note that $\mathrm{IgG}$ antibodies directed against one form of $\alpha$-gal A are reported to cross-react with the other form. ${ }^{97}$ Although the impact of these antibodies on clinical response remains unresolved, at least one case of a severe infusion reaction has been reported in an IgG-positive patient who switched from agalsidase alfa to agalsidase beta. ${ }^{98}$ This patient developed low-titer IgG antibodies (titer $=200$ ) during therapy with agalsidase alfa and experienced an anaphylactoid reaction during his second infusion of agalsidase beta and again on rechallenge. No antiagalsidase beta $\operatorname{IgE}$ antibodies were found, and skin tests were negative.

\section{DISCUSSION}

Agalsidase alfa and agalsidase beta are similar, but not identical, formulations of $\alpha$-gal A for the treatment of Fabry disease. ${ }^{25}$ Ideally, the results of head-to-head clinical trials would be used to compare the clinical efficacies of the two drugs. Two studies have reported on patients treated with either agalsidase alfa or agalsidase beta. ${ }^{42,43}$ In the first study, ${ }^{42}$ the administered dose of agalsidase beta $(0.2 \mathrm{mg} / \mathrm{kg} \mathrm{EOW})$ was lower than the approved regimen. In the second study, the results of agalsidase alfa at its approved dose $(0.2 \mathrm{mg} / \mathrm{kg}$ EOW) were pooled with those of agalsidase beta at 0.2 $\mathrm{mg} / \mathrm{kg}$ EOW for the comparison with agalsidase beta at $1.0 \mathrm{mg} / \mathrm{kg}$ EOW. ${ }^{42}$ One head-to-head clinical study, The Canadian Fabry Disease Initiative, was initiated in 2007.99 This study involves a randomized assignment of ERT-naïve patients with Fabry disease to either agalsidase alfa or agalsidase beta at their respective standard doses and routinely monitors major organ involvement. Preliminary results from this study have been posted on the Canadian Institute of Health Research website (available at: http:/www.cihr-irsc.gc.ca/e/39674.html), but no peer-reviewed results have been published from this study.

The results of the present review did not reveal any clear differences in clinical responses among patients treated with agalsidase alfa or agalsidase beta. To date, there have been more published studies of agalsidase alfa than agalsidase beta in special populations such as female patients and young patients. The reported results in treated patients support the benefits of early initiation of ERT. For example, both drugs stabilize kidney function in patients with moderate kidney disease but seem to have less effect in patients with advanced disease as evi- 
denced by proteinuria $>1$ g/day (Fig. 2). ${ }^{32,34}$ Similarly, a better cardiac response was seen in patients without evidence of myocardial fibrosis at baseline. ${ }^{61,64}$ Conceptually, early initiation of ERT, even before major organ damage is evident, should provide optimal benefit, but no evidence yet exists that this strategy will result in better long-term outcomes.

ERT is but one part of the overall management of Fabry disease. Adjunct therapy should be considered when appropriate. For example, anticonvulsant drugs may be used to treat neuropathic pain; dietary restrictions, $\mathrm{H} 2$ blockers, and proton pump inhibitors may relieve some gastrointestinal problems; and antiplatelet agents may reduce the risk of myocardial infarction and stroke. Of great interest is the use of ACE inhibitors or ARBs. These drugs are now considered standard of care for patients with nephropathy, regardless of the etiology, and may reduce proteinuria independent of their effect on blood pressure. ${ }^{100}$ A single small study of these agents has been conducted with patients with Fabry disease receiving agalsidase beta, and its results suggest that adding this treatment to ERT may extend the benefits of ERT to patients with more advanced kidney dysfunction. ${ }^{55}$ A prospective observational study is underway in which patients with Fabry disease with kidney disease and proteinuria who are currently receiving agalsidase beta will be treated with an ACE inhibitor or an ARB (available at: http:// www.clinicaltrials.gov/ct2/show/NCT00446862?term = fabrazyme\& rank $=13$ ). The primary purpose of this study is to determine whether titrating the dose of an ACE inhibitor or ARB to reduce urine protein/creatinine to a ratio below 0.5 will slow the decline in GFR over 24 months. In the early studies of ERT in Fabry disease, the use of ACE inhibitors or ARBs was not dictated by protocol, and their effect on renal outcomes could not be formerly assessed. ${ }^{30,32,34,35,54}$ It should be noted that patients with Fabry disease typically have normal blood pressure, and some patients may not tolerate the hypotensive activity of these agents.

ERT for Fabry disease has been commercially available for more than 8 years, and randomized, placebo-controlled clinical trials will be difficult to conduct because few patients will be ERT naïve. In addition, ethical concerns exist about enrolling patients in a placebo-controlled trial when approved treatment is available. Patient registries and outcome surveys have the potential to add to our assessment of the safety and efficacy of ERT because they have the goal of acquiring data from a large number of patients at various stages of the disease process over long periods of follow-up. Despite this potential, it must be noted that the patient population enrolled in these registries may not reflect the entire Fabry disease population because asymptomatic patients may be underrepresented. In addition, data collection in these registries is often incomplete, and there is little standardization of test methods. Despite these limitations, reports from the Fabry Outcome Survey (FOS) generally confirm the results of the prospective clinical studies of agalsidase alfa. For example, in the most recent report from FOS, Mehta et al. ${ }^{101}$ reported that during 5 years of treatment with agalsidase alfa, stabilization or improvement was seen in men and women for LVM, mean fractional shortening, health-related quality of life, and neuropathic pain. Beneficial effects of agalsidase alfa have also been reported in FOS for health-related quality of life, ${ }^{102}$ gastrointestinal problems, ${ }^{103}$ and hearing. ${ }^{104}$ Other reports on the effects of agalsidase beta in the Fabry Registry are anticipated. Long-term registry and survey data may provide additional useful information about the safety and efficacy of ERT. Importantly, periodic reports from these surveys and registries are requested by the regulating authorities for their continuing evaluation of ERT for Fabry disease.

\section{CONCLUSIONS}

ERT represents an important milestone in the management of Fabry disease, and this review of clinical outcomes illustrates several important points. The published reports strongly support clinical benefit with ERT, but considerable variation in the response to ERT exists. Such variation is not surprising given the heterogeneous phenotypic expression in patients of all ages with Fabry disease and the lack of clear guidelines about which patients to treat and when to initiate treatment. It will be important to establish treatment guidelines and therapeutic goals for the various patient populations to manage expectations and to aid in the evaluation of the results of ERT in the clinical practice environment. The potential difference in antigenicity between the two approved drugs and the influence of antibodies on the clinical responses have not been conclusively addressed. Until these issues are resolved, clinical responses remain a better indicator than biochemical changes when evaluating the response to ERT.

Much remains to be learned about ERT and Fabry disease. For example, the optimum time to initiate ERT has not yet been determined, and no guidance about when or if to switch patients from one drug to the other in the face of apparent clinical failure or intolerance has been published. It is hoped that future studies will address these important issues.

\section{Limitation of this review}

This report is based on a review of the published literature, which itself is subject to bias. For example, negative or neutral studies are less likely to be published. With the exception of the four double-blinded, placebo-controlled studies, ${ }^{29,31,33,35}$ the quality of the remaining studies was variable. Patients included in randomized clinical trials could have been included in the FOS or Fabry Registry. For this reason, results from these registries were only included in the commentary section. This article was read by Shire HGT for statutory reasons. All the authors certify that the manuscript was not modified in any way after this reading.

\section{ACKNOWLEDGMENTS}

The authors represent the Global Advisory Board, which is an international panel of clinicians with extensive clinical experience of Fabry disease. The authors thank Shire HGT for the support given to the Global Advisory Board for the development of this manuscript. Dr. Parini thanks Fondazione Pierfranco and Luisa Mariani of Milano for their financial support and assistance. The authors also acknowledge the editorial assistance provided by Edward Weselcouch, $\mathrm{PhD}$, and Erika Meyer, PhD, of PharmaWrite (Princeton, NJ), which was funded by Shire HGT. Shire HGT reviewed the manuscript to ensure the accuracy of all statements regarding Shire HGTsponsored clinical trials but had no other role in the literature review or the drafting and revising of the manuscript. The authors are responsible for the interpretation presented in this review. All authors have approved the final version of the manuscript and are fully responsible for its content.

\section{REFERENCES}

1. Brady RO, Gal AE, Bradley RM, Martensson E, Warshaw AL, Laster L. Enzymatic defect in Fabry's disease. Ceramidetrihexosidase deficiency. N Engl J Med 1967;276:1163-1167. 
2. Clarke JT. Narrative review: Fabry disease. Ann Intern Med 2007;146:425433

3. Schiffmann R. Fabry disease. Pharmacol Ther 2009;122:65-77.

4. Zarate YA, Hopkin RJ. Fabry's disease. Lancet 2008;372:1427-1435

5. Ries M, Gupta S, Moore DF, et al. Pediatric Fabry disease. Pediatrics 2005;115:e344-e355.

6. Ries M, Ramaswami U, Parini R, et al. The early clinical phenotype of Fabry disease: a study on 35 European children and adolescents. Eur J Pediatr 2003;162:767-772.

7. Ramaswami U, Whybra C, Parini R, et al. Clinical manifestations of Fabry disease in children: data from the Fabry Outcome Survey. Acta Paediatr 2006;95:86-92.

8. Schiffmann R, Warnock DG, Banikazemi M, et al. Fabry disease: progression of nephropathy, and prevalence of cardiac and cerebrovascular events before enzyme replacement therapy. Nephrol Dial Transplant 2009;24: 2102-2111.

9. Thadhani R, Wolf M, West ML, et al. Patients with Fabry disease on dialysis in the United States. Kidney Int 2002;61:249-255.

10. MacDermot KD, Holmes A, Miners AH. Anderson-Fabry disease: clinical manifestations and impact of disease in a cohort of 98 hemizygous males. J Med Genet 2001;38:750-760.

11. Ortiz A, Oliveira JP, Waldek S, Warnock DG, Cianciaruso B, Wanner C. Nephropathy in males and females with Fabry disease: cross-sectional description of patients before treatment with enzyme replacement therapy. Nephrol Dial Transplant 2008;23:1600-1607.

12. Ortiz A, Cianciaruso B, Cizmarik M, et al. End-stage renal disease in patients with Fabry disease: natural history data from the Fabry Registry. Nephrol Dial Transplant 2010;25:769-775.

13. Kampmann C, Linhart A, Baehner F, et al. Onset and progression of the Anderson-Fabry disease related cardiomyopathy. Int J Cardiol 2008;130: 367-373

14. Sims K, Politei J, Banikazemi M, Lee P. Stroke in Fabry disease frequently occurs before diagnosis and in the absence of other clinical events. Natural history data from the Fabry registry. Stroke 2009;40:788-794.

15. Mehta A, Clarke JT, Giugliani R, et al. Natural course of Fabry disease: changing pattern of causes of death in FOS-Fabry Outcome Survey. J Med Genet 2009;46:548-552.

16. Waldek S, Patel MR, Banikazemi M, Lemay R, Lee P. Life expectancy and cause of death in males and females with Fabry disease: findings from the Fabry Registry. Genet Med 2009;11:790-796.

17. Hopkin RJ, Bissler J, Banikazemi M, et al. Characterization of Fabry disease in 352 pediatric patients in the Fabry Registry. Pediatr Res 2008; 64:550-555

18. Kampmann C, Wiethoff CM, Whybra C, Bachner FA, Mengel E, Beck M. Cardiac manifestations of Anderson-Fabry disease in children and adolescents. Acta Paediatr 2008;97:463-469.

19. Ries M, Clarke JT, Whybra C, et al. Enzyme-replacement therapy with agalsidase alfa in children with Fabry disease. Pediatrics 2006;118:924-932.

20. Grewal RP. Stroke in Fabry's disease. J Neurol 1994;241:153-156.

21. Gold KF, Pastores GM, Botteman MF, et al. Quality of life of patients with Fabry disease. Qual Life Res 2002;11:317-327.

22. Miners AH, Holmes A, Sherr L, Jenkinson C, MacDermot KD. Assessment of health-related quality-of-life in males with Anderson Fabry disease before therapeutic intervention. Qual Life Res 2002;11:127-133.

23. Street NJ, Yi MS, Bailey LA, Hopkin RJ. Comparison of health-related quality of life between heterozygous women with Fabry disease, a healthy control population, and patients with other chronic disease. Genet Med 2006;8:346-353.

24. Schiffmann R, Murray GJ, Treco D, et al. Infusion of $\alpha$-galactosidase A reduces tissue globotriaosylceramide storage in patients with Fabry disease. Proc Natl Acad Sci USA 2000;97:365-370.

25. Lee $\mathrm{K}$, Jin $\mathrm{X}$, Zhang $\mathrm{K}$, et al. A biochemical and pharmacological comparison of enzyme replacement therapies for the glycolipid storage disorder Fabry disease. Glycobiology 2003;13:305-313.

26. European Medicines Agency. Fabrazyme $\mathbb{R}$ — summary of product characteristics. Available at: http://www.emea.europa.eu/humandocs/Humans/ EPAR/fabrazyme/fabrazyme.htm. Accessed September 30, 2009.

27. European Medicines Agency. Replagal $($ — summary of product characteristics. Available at: http://www.emea.europa.eu/humandocs/Humans/ EPAR/replagal/replagal.htm. Accessed September 30, 2009.

28. European Medicines Agency. Fabrazyme: procedural steps taken and scientific information after the authorisation. Available at: http://www. ema.europa.eu/humandocs/PDFs/EPAR/fabrazyme/101201en8b.pdf. Accessed September 30, 2009.

29. Schiffmann R, Kopp JB, Austin HA 3rd, et al. Enzyme replacement therapy in Fabry disease: a randomized controlled trial. JAMA 2001;285:27432749

30. Schiffmann R, Ries M, Timmons M, Flaherty JT, Brady RO. Long-term therapy with agalsidase alfa for Fabry disease: safety and effects on renal function in a home infusion setting. Nephrol Dial Transplant 2006;21:345354
31. Hughes DA, Elliott PM, Shah J, et al. Effects of enzyme replacement therapy on the cardiomyopathy of Anderson-Fabry disease: a randomized, double-blind, placebo-controlled clinical trial of agalsidase-alfa. Heart 2008;94:153-158.

32. West M, Nicholls K, Mehta A, et al. Agalsidase alfa and kidney dysfunction in Fabry disease. J Am Soc Nephrol 2009;20:1132-1139.

33. Eng CM, Guffon N, Wilcox WR, et al. Safety and efficacy of recombinant human $\alpha$-galactosidase A -replacement therapy in Fabry's disease. $N$ Engl $J$ Med 2001;345:9-16.

34. Germain DP, Waldek S, Banikazemi M, et al. Sustained, long-term renal stabilization after 54 months of agalsidase beta therapy in patients with Fabry disease. J Am Soc Nephrol 2007;18:1547-1557.

35. Banikazemi M, Bultas J, Waldek S, et al. Agalsidase-beta therapy for advanced Fabry disease: a randomized trial. Ann Intern Med 2007;146:77-86.

36. Ramaswami U, Wendt S, Pintos-Morell G, et al. Enzyme replacement therapy with agalsidase alfa in children with Fabry disease. Acta Paediatr 2007;96:122-127.

37. Wraith JE, Tylki-Szymanska A, Guffon N, et al. Safety and efficacy of enzyme replacement therapy with agalsidase beta: an international, openlabel study in pediatric patients with Fabry disease. J Pediatr 2008;152: 563-570.

38. Whybra C, Miebach E, Mengel E, et al. A 4-year study of the efficacy and tolerability of enzyme replacement therapy with agalsidase alfa in 36 women with Fabry disease. Genet Med 2009;11:441-449.

39. Mehta A, West ML, Pintos-Morell G, et al. Therapeutic goals in the treatment of Fabry disease. Genet Med 2010;12:713-720.

40. Benichou B, Goyal S, Sung C, Norfleet AM, O'Brien F. A retrospective analysis of the potential impact of IgG antibodies to agalsidase beta on efficacy during enzyme replacement therapy for Fabry disease. Mol Genet Metab 2009;96:4-12.

41. Kovacevic-Preradovic T, Zuber M, Attenhofer Jost CH, et al AndersonFabry disease: long-term echocardiographic follow-up under enzyme replacement therapy. Eur J Echocardiogr 2008;9:729-735.

42. Vedder AC, Breunig F, Donker-Koopman WE, et al. Treatment of Fabry disease with different dosing regimens of agalsidase: effects on antibody formation and GL-3. Mol Genet Metab 2008;94:319-325

43. Vedder AC, Linthorst GE, Houge G, et al. Treatment of Fabry disease: outcome of a comparative trial with agalsidase alfa or beta at a dose of 0.2 $\mathrm{mg} / \mathrm{kg}$. PLoS ONE 2007;2:e598.

44. Mignani R, Feriozzi S, Pisani A, et al. Agalsidase therapy in patients with Fabry disease on renal replacement therapy: a nationwide study in Italy. Nephrol Dial Transplant 2008;23:1628-1635.

45. Eto Y, Ohashi T, Utsunomiya Y, et al. Enzyme replacement therapy in Japanese Fabry disease patients: the results of a phase 2 bridging study. $J$ Inherit Metab Dis 2005;28:575-583.

46. Schiffmann R, Floeter MK, Dambrosia JM, et al. Enzyme replacement therapy improves peripheral nerve and sweat function in Fabry disease. Muscle Nerve 2003;28:703-710.

47. Hilz MJ, Brys M, Marthol H, Stemper B, Dutsch M. Enzyme replacement therapy improves function of C-, Aä-, and Aâ-nerve fibers in Fabry neuropathy. Neurology 2004;62:1066-1072.

48. Schiffmann R, Hauer P, Freeman B, et al. Enzyme replacement therapy and intraepidermal innervation density in Fabry disease. Muscle Nerve 2006; 34:53-56.

49. Palla A, Hegemann S, Widmer U, Straumann D. Vestibular and auditory deficits in Fabry disease and their response to enzyme replacement therapy. J Neurol 2007;254:1433-1442.

50. Hajioff D, Enever Y, Quiney R, Zuckerman J, Mackermot K, Mehta A. Hearing loss in Fabry disease: the effect of agalsidase alfa replacement therapy. J Inherit Metab Dis 2003;26:787-794.

51. Choi JH, Cho YM, Suh KS, et al. Short-term efficacy of enzyme replacement therapy in Korean patients with Fabry disease. J Korean Med Sci 2008;23:243-250.

52. Lubanda JC, Anijalg E, Bzduch V, Thurberg BL, Benichou B, TylkiSzymanska A. Evaluation of a low dose, after a standard therapeutic dose, of agalsidase beta during enzyme replacement therapy in patients with Fabry disease. Genet Med 2009;11:256-264

53. Wilcox WR, Banikazemi M, Guffon N, et al. Long-term safety and efficacy of enzyme replacement therapy for Fabry disease. Am J Hum Genet 2004;75:65-74.

54. Breunig F, Weidemann F, Strotmann J, Knoll A, Wanner C. Clinical benefit of enzyme replacement therapy in Fabry disease. Kidney Int 2006;69: $1216-1221$

55. Tahir H, Jackson LL, Warnock DG. Antiproteinuric therapy and Fabry nephropathy: sustained reduction of proteinuria in patients receiving enzyme replacement therapy with agalsidase-beta. J Am Soc Nephrol 2007; 18:2609-2617.

56. Pastores GM, Boyd E, Crandall K, Whelan A, Piersall L, Barnett N. Safety and pharmacokinetics of agalsidase alfa in patients with Fabry disease and end-stage renal disease. Nephrol Dial Transplant 2007:22:1920-1925.

57. Pisani A, Spinelli L, Sabbatini M, et al. Enzyme replacement therapy in 
Fabry disease patients undergoing dialysis: effects on quality of life and organ involvement. Am J Kidney Dis 2005;46:120-127.

58. Koskenvuo JW, Hartiala JJ, Nuutila P, et al. Twenty-four-month alphaGalactosidase A replacement therapy in Fabry disease has only minimal effects on symptoms and cardiovascular parameters. $J$ Inherit Metab Dis 2008;31:432-441.

59. Elliott PM, Kindler H, Shah JS, et al. Coronary microvascular dysfunction in male patients with Anderson-Fabry disease and the effect of treatment with á galactosidase A. Heart 2006;92:357-360.

60. Imbriaco M, Pisani A, Spinelli L, et al. Effects of enzyme replacement therapy in patients with Anderson-Fabry disease: a prospective long term cardiac magnetic resonance imaging study. Heart 2009;95:1103-1107.

61. Weidemann F, Niemann M, Breunig F, et al. Long-term effects of enzyme replacement therapy on Fabry cardiomyopathy: evidence for a better outcome with early treatment. Circulation 2009;119:524-529.

62. Spinelli L, Pisani A, Sabbatini M, et al. Enzyme replacement therapy with agalsidase beta improves cardiac involvement in Fabry's disease. Clin Genet 2004;66:158-165.

63. Weidemann F, Breunig F, Beer M, et al. Improvement of cardiac function during enzyme replacement therapy in patients with Fabry disease: a prospective strain rate imaging study. Circulation 2003;108:1299-1301.

64. Beer M, Weidemann F, Breunig F, et al. Impact of enzyme replacement therapy on cardiac morphology and function and late enhancement in Fabry's cardiomyopathy. Am J Cardiol 2006;97:1515-1518.

65. Kalliokoski RJ, Kantola I, Kalliokoski KK, et al. The effect of 12-month enzyme replacement therapy on myocardial perfusion in patients with Fabry disease. J Inherit Metab Dis 2006;29:112-118.

66. Baehner F, Kampmann C, Whybra C, Miebach E, Wiethoff CM, Beck M. Enzyme replacement therapy in heterozygous females with Fabry disease: results of a phase IIIB study. $J$ Inherit Metab Dis 2003;26:617-627.

67. Jardim L, Vedolin L, Schwartz IV, et al. CNS involvement in Fabry disease: clinical and imaging studies before and after 12 months of enzyme replacement therapy. J Inherit Metab Dis 2004;27:229-240.

68. Jardim LB, Aesse F, Vedolin LM, et al. White matter lesions in Fabry disease before and after enzyme replacement therapy: a 2-year follow-up. Arq Neuropsiquiatr 2006;64:711-717.

69. Moore DF, Scott LT, Gladwin MT, et al. Regional cerebral hyperfusion and nitric oxide pathway dysregulation in Fabry disease: reversal by enzyme replacement therapy. Circulation 2001;104:1506-1512.

70. Moore DF, Altarescu G, Herscovitch P, Schiffmann R. Enzyme replacement reverses abnormal cerebrovascular responses in Fabry disease. $B M C$ Neurol 2002;2:4

71. Gupta SN, Ries M, Murray GJ, et al. Skin-impedance in Fabry Disease: a prospective, controlled, non-randomized clinical study. BMC Neurol 2008; $8: 41$.

72. Jardim LB, Gomes I, Netto CB, et al. Improvement of sympathetic skin responses under enzyme replacement therapy in Fabry disease. $J$ Inherit Metab Dis 2006;29:653-659.

73. Dehout F, Roland D, Treille de Granseigne S, Guillaume B, Van Maldergem L. Relief of gastrointestinal symptoms under enzyme replacement therapy in patients with Fabry disease. J Inherit Metab Dis 2004;27:499505.

74. Parini R, Rigoldi M, Santus F, et al. Enzyme replacement therapy with agalsidase alfa in a cohort of Italian patients with Anderson-Fabry disease: testing the effects with the Mainz Severity Score Index. Clin Genet 2008; 74:260-266.

75. Whybra C, Kampmann C, Krummenauer F, et al. The Mainz Severity Score Index: a new instrument for quantifying the Anderson-Fabry disease phenotype, and the response of patients to enzyme replacement therapy. Clin Genet 2004;65:299-307.

76. Bierer G, Balfe D, Wilcox WR, Mosenifar Z. Improvement in serial cardiopulmonary exercise testing following enzyme replacement therapy in Fabry disease. J Inherit Metab Dis 2006;29:572-579.

77. Tondel C, Bostad L, Hirth A, Svarstad E. Renal biopsy findings in children and adolescents with Fabry disease and minimal albuminuria. Am J Kidney Dis 2008;51:767-776.

78. Branton MH, Schiffmann R, Sabnis SG, et al. Natural history of Fabry renal disease: influence of á-galactosidase A activity and genetic mutations on clinical course. Medicine (Baltimore) 2002;81:122-138.

79. Schwarting A, Dehout F, Feriozzi S, Beck M, Mehta A, Sunder-Plassmann G; European FOS Investigators. Enzyme replacement therapy and renal function in 201 patients with Fabry disease. Clin Nephrol 2006;66:77-84.

80. Tsakiris D, Simpson HK, Jones EH, et al. Report on management of renal failure in Europe, XXVI, 1995. Rare diseases in renal replacement therapy in the ERA-EDTA registry. Nephrol Dial Transplant 1996; 11(suppl 7): $4-20$.

81. Linhart A, Elliott PM. The heart in Anderson-Fabry disease and other lysosomal storage disorders. Heart 2007;93:528-535.

82. Weidemann F, Niemann M, Herrmann S, et al. A new echocardiographic approach for the detection of non-ischaemic fibrosis in hypertrophic myocardium. Eur Heart J 2007;28:3020-3026.

83. Toro R, Perez-Isla L, Doxastaquis G, et al. Clinical usefulness of tissue Doppler imaging in predicting preclinical Fabry cardiomyopathy. Int $J$ Cardiol 2009;132:38-44

84. Weidemann F, Breunig F, Beer M, et al. The variation of morphological and functional cardiac manifestation in Fabry disease: potential implications for the time course of the disease. Eur Heart $J$ 2005;26:1221-1227.

85. Moore DF, Altarescu G, Ling GS, et al. Elevated cerebral blood flow velocities in Fabry disease with reversal after enzyme replacement. Stroke 2002;33:525-531.

86. Wilcox WR, Oliveira JP, Hopkin RJ, et al. Females with Fabry disease frequently have major organ involvement: lessons from the Fabry Registry. Mol Genet Metab 2008;93:112-128.

87. Eng CM, Fletcher J, Wilcox WR, et al. Fabry disease: baseline medical characteristics of a cohort of 1765 males and females in the Fabry Registry. J Inherit Metab Dis 2007;30:184-192.

88. Mehta A, Ricci R, Widmer U, et al. Fabry disease defined: baseline clinical manifestations of 366 patients in the Fabry Outcome Survey. Eur J Clin Invest 2004;34:236-242.

89. Giannini EH, Mehta AB, Hilz MJ, et al. A validated disease severity scoring system for Fabry disease. Mol Genet Metab 2010;99:283-290.

90. Whybra C, Kampmann C, Willers I, et al. Anderson-Fabry disease: clinical manifestations of disease in female heterozygotes. $J$ Inherit Metab Dis 2001;24:715-724

91. Wang RY, Lelis A, Mirocha J, Wilcox WR. Heterozygous Fabry women are not just carriers, but have a significant burden of disease and impaired quality of life. Genet Med 2007;9:34-45.

92. Pintos-Morell G, Beck M. Fabry disease in children and the effects of enzyme replacement treatment. Eur J Pediatr 2009;168:1355-1363.

93. Schiffmann R, Martin RA, Reimschisel T, et al. Four-year prospective clinical trial of agalsidase alfa in children with Fabry disease. $J$ Pediatr 2010;156:832-837, 837.e1.

94. Ohashi T, Sakuma M, Kitagawa T, Suzuki K, Ishige N, Eto Y. Influence of antibody formation on reduction of globotriaosylceramide (GL-3) in urine from Fabry patients during agalsidase beta therapy. Mol Genet Metab 2007;92:271-273

95. Bekri S, Lidove O, Jaussaud R, Knebelmann B, Barbey F. The role of ceramide trihexoside (globotriaosylceramide) in the diagnosis and follow-up of the efficacy of treatment of Fabry disease: a review of the literature. Cardiovasc Hematol Agents Med Chem 2006;4:289-297.

96. Young E, Mills K, Morris P, et al. Is globotriaosylceramide a useful biomarker in Fabry disease? Acta Paediatr Suppl 2005;94:51-54.

97. Linthorst GE, Hollak CE, Donker-Koopman WE, Strijland A, Aerts JM. Enzyme therapy for Fabry disease: neutralizing antibodies toward agalsidase alpha and beta. Kidney Int 2004;66:1589-1595

98. Tesmoingt C, Lidove O, Reberga A, et al. Enzyme therapy in Fabry disease: severe adverse events associated with anti-agalsidase cross-reactive $\operatorname{lgG}$ antibodies. Br J Clin Pharmacol 2009;68:765-769.

99. Sirrs S, Clarke JT, Bichet DG, et al. Baseline characteristics of patients enrolled in the Canadian Fabry Disease Initiative. Mol Genet Metab 2010; 99:367-373.

100. Remuzzi G, Perico N, Macia M, Ruggenenti P. The role of renin-angiotensin-aldosterone system in the progression of chronic kidney disease. Kidney Int Suppl 2005;S57-S65

101. Mehta A, Beck M, Elliott P, et al. Enzyme replacement therapy with agalsidase alfa in patients with Fabry's disease: an analysis of registry data. Lancet 2009;374:1986-1997.

102. Hoffmann B, Garcia de Lorenzo A, Mehta A, Beck M, Widmer U, Ricci R. Effects of enzyme replacement therapy on pain and health related quality of life in patients with Fabry disease: data from FOS (Fabry Outcome Survey). J Med Genet 2005;42:247-252.

103. Hoffmann B, Schwarz M, Mehta A, Keshav S. Gastrointestinal symptoms in 342 patients with Fabry disease: prevalence and response to enzyme replacement therapy. Clin Gastroenterol Hepatol 2007;5:1447-1453.

104. Hajioff D, Hegemannn S, Conti G, et al. Agalsidase alpha and hearing in Fabry disease: data from the Fabry Outcome Survey. Eur J Clin Invest 2006;36:663-667. 